\title{
Topography of methanogenic subpopulations in a microbial consortium adapting to thermophilic conditions
}

\author{
Alberto J. L. Macario, ${ }^{1,2}$ Frans A. Visser, ${ }^{1,3}$ Jules B. Van Lier ${ }^{4}$ \\ and Everly Conway de Macario ${ }^{1,2 *}$ \\ ${ }^{1}$ Wadsworth Center for Laboratories and Research, New York State Department of Health and ${ }^{2}$ School of Public Health, \\ SUNY Albany, Albany, New York 12201-0509, USA \\ ${ }^{3}$ Department of Microbiology and ${ }^{4}$ Department of Environmental Technology, Agricultural University of Wageningen, \\ 6703 Wageningen, The Netherlands
}

(Received 22 January 1991; revised 9 April 1991; accepted 4 June 1991)

\begin{abstract}
The microanatomy of a granular, methanogenic, microbial consortium (granule) was investigated by applying histochemical techniques and light microscopy. The granules were obtained from a full-scale, mesophilic, upflow anaerobic-sludge blanket (UASB) bioreactor and were inoculated into laboratory-scale counterparts with a defined substrate in which they were maintained for several weeks before shifting to thermophilic conditions. Samples for analysis were collected from the original inoculum, and from the laboratory-scale bioreactors before and after the temperature shift. Four months after this shift, the basic architectural plan of the granules was found to comprise a core or medulla, and a peripheral zone or cortex bounded by denser layers, and a spongy matrix formed by microbes and intercellular material. Also, five methanogenic subpopulations known to occur in these 4month thermophilic granules were mapped to elucidate their spatial arrangement using immunofluorescence with antibody probes of predefined specificity spectra on histologic thin sections. Each subpopulation silowed a distinctive distribution pattern; e.g. elongated surface and inner colonies for the methanogen antigenically related to Methanobacterium thermoautotrophicum $\Delta \mathrm{H}$, packets and cellular cords for the methanosarcina related to Methanosarcina thermophila TM1, bundles for Methanothrix rods, and dense or sparse lawns for the methanogens antigenically related to Methanobrevibacter arboriphilus $\mathrm{AZ}$ and Methanobrevibacter smithii $\mathrm{ALI}$, respectively. These features were absent from, or much less developed in, the original inoculum granules, and before the temperature shift or even 1 week thereafter. All granules showed the same basic architecture involving a cortex and a medulla, but the inner texture of the mesophilic granules was considerably more compact than that of the 4-month thermophilic granules. Thus, the topography of methanogenic subpopulations and some structural details of the 4month thermophilic granules seem to be the result of adaptation to enrivonmental factors such as temperature, the same way as the array of methanogenic species and their numbers were found to be in previous work.
\end{abstract}

\section{Introduction}

Microbial associations in consortia have been the subject of study by several laboratories (Bochem et al., 1982; Chartrain \& Zeikus, 1986; Dubourguier et al., 1988; Dolfing, 1987; MacLeod et al., 1990; Stams et al., 1989; Zellner \& Winter, 1987). Consortia may appear as films or granules, and are formed by groups of different microbes that associate to build up a functional unit. These associations occur in many natural and manufac-

Abbreviations: UASB, upflow anaerobic-sludge blanket. tured ecosystems (Costerton et al., 1987; Ford \& Mitchell, 1990; Hamilton, 1987; Hulshoff Pol et al., 1983; Margulis et al., 1986; de Zeeuw, 1988), but they are incompletely characterized and their mechanism of formation is poorly understood. To make progress in these areas, experimental models are necessary. In this regard, anaerobic methanogenic bioreactors are convenient since substrate (i.e. carbon and energy sources) and temperature can be controlled. In these bioreactors, at least three distinct groups of microbes participate: acidogenic, acetogenic and methanogenic bacteria (Chartrain \& Zeikus, 1986; Dubourguier et al., 1988; 
Novaes, 1986; Prensier et al., 1988; Stams et al., 1989; Toerien \& Hattingh, 1969).

We (Visser et al., 1991) have recently identified and quantified the methanogenic bacteria (methanogens) present in cell suspensions prepared from granules of mesophilic, upflow anaerobic-sludge blanket (UASB) bioreactors (Hulshoff Pol et al., 1983; Lettinga et al., 1980) and in cell suspensions from the same granules after shifting the temperature to achieve thermophilic conditions, in a known substrate. The granules were examined at various time-points before and after increasing the temperature from 38 to $55^{\circ} \mathrm{C}$ to follow the response of the methanogenic subpopulations. These showed changes and by the end of the fourth month under thermophilic conditions, the methanogenic flora was different from that found before the temperature shift. The consortium had undergone readjustments to adapt to the increase in temperature. Structural changes were visible in histologic sections of granules and are reported here.

Ultrastructural fine details and the overall layout of different microbial morphotypes in bioreactor granules have been examined by transmission and scanning electron microscopy (Bochem et al., 1982; Dubourguier et al., 1988; MacLeod et al., 1990; Stams et al., 1989). There is, however, little information on the microanatomy of these granules as would be revealed by histochemistry and light microscopy of thin sections. Studies at this level of resolution are necessary to identify, and to map within the granule as a whole, the microbial populations as they occur in situ and thus learn about the size, shape and distribution of their colonies in relation to each other. Unambiguous mapping of microbial species throughout the granules is still incomplete, most likely because of the general unavailability of probes for identification in situ (Prensier et al., 1988).

In this work we describe structural findings applying standard histochemical techniques on thin sections and light microscopy. We also show the topography of predominant methanogenic subpopulations using antibody probes of predefined specificity spectra and immunohistochemical procedures.

\section{Methods}

Granules. A series of 5 litre laboratory-scale UASB bioreactors with

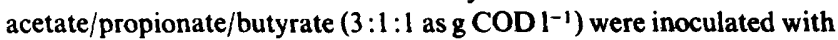
granules from a full-scale ( 1700 litre) mesophilic UASB bioreactor-fed wastewater from a potato-processing plant (Visser et al., 1991). The experimental laboratory bioreactors were run for 2 to 4 weeks after inoculation at $38^{\circ} \mathrm{C}$ and then the temperature was increased to achieve thermophilic conditions in $3 \mathrm{~h} 15 \mathrm{~min}$ (this was considered day 1 for the purpose of sample designation). This work focuses on granules obtained 4 months after increasing the temperature from 38 to $55^{\circ} \mathrm{C}$ and which are referred to as 4 -month thermophilic granules. For comparison, other samples from the same bioreactor were examined (collected $10 \mathrm{~d}$ before and $7 \mathrm{~d}$ after the temperature shift), as well as samples from the inoculum granules and from the other laboratory bioreactors also run under thermophilic conditions for several months.

Histochemistry. Thin sections of granules were prepared from blocks as per standard procedures (Culling et al., 1985; Luna, 1968) with minor modifications. A $1 \mathrm{ml}$ vol. of wet granules was fixed in $10 \mathrm{ml}$ of Telly's solution for $8 \mathrm{~h}$. The fluid was then removed by filtering the granules through a piece of medical gauze on top of a beaker. The fixed granules were then transferred, using a spatula, onto a piece of tissue paper. The tissue paper was then folded until the granules were completely surrounded. The granules were then transferred to a HistoPrep capsule (Fisher Scientific) and placed in $70 \%(\mathrm{v} / \mathrm{v})$ ethanol for $6 \mathrm{~h}$ Next, the granules were dehydrated and waxed in an automated Autotechnicon Ultra (Technicon Instruments). Following this process, the tissue paper was removed and the granules were embedded in paraffin (Ameraffin Tissue Embedding Medium, Stephens Scientific Division of Cornwell Corp.) in tissue-embedding moulds topped with an Histo-Prep embedding ring (Fisher Scientific) using a tissueembedding centre (Tissue Tek II System, Miles Laboratories). Sections $(5 \mu \mathrm{m})$ were obtained from cooled blocks using a model 820 microtome (American Optical). The ribbon of cut sections was placed on a tissuefloating bath (Boekel) and then collected on the circles of printed glass SIA-slides (Cel-Line Associates) (Macario \& Conway de Macario, 1985) with heavy Teflon coating and three circles $14 \mathrm{~mm}$ across per slide. The sections were fixed to the slides by drying at $60^{\circ} \mathrm{C}$ for $2 \mathrm{~h}$, which also removed part of the wax. The rest of the wax was removed using a clearing-area device (Tissue Tek II). The sections were then stained with either one or another of these procedures: haematoxylin/ eosin, Gram (Brown and Brenns'), periodic acid/Schiff (PAS) and silver impregnation (Grocott's) following standard protocols (Luna, 1968).

Antibody probes and immunohistochemistry. The same comprehensive panel of calibrated antibody probes (Macario \& Conway de Macario, 1983, 1985) for reference species (Balch et al., 1979; Boone \& Whitman, 1988) used for quantification of methanogens in previous work (Macario \& Conway de Macario, 1988) was utilized for immunohistochemistry in thin sections following published procedures (Culling $e t$ $a l ., 1985)$. The results reported here were obtained using indirect immunofluorescence with the probes for Methanobacterium thermoautotrophicum $\Delta \mathrm{H}$, Methanosarcina thermophila TM1, Methanothrix soehngenii Opfikon, Methanobrevibacter arboriphilus AZ and Methanobrevibacter smithii ALI (because in our previous study the predominant methanogens found in cell suspensions from the 4-month thermophilic granules were antigenically related to these five reference organisms). An antibody probe for Methanosarcina barkeri $\mathrm{W}$ was also used because the sarcina found in cell suspensions from the granules before the temperature shift was antigenically related to this reference organism.

Microscopy and microphotography. Thin sections stained by the methods given above, or reacted with the antibody probes or negative control reagents (indirect immunofluorescence) were examined and photographed with a Zeiss Axiophot microscope (Carl Zeiss) using either bright-field or epifluorescence illumination, and $20 \times, 40 \times$ and $100 \times$ objectives. Microphotographs were taken using either Kodachrome 64 ASA, or Ektachrome 400 ASA for immunofluorescence. The sections were examined to record overall structure as well as details, particularly abundance and morphology of microbes and microbial colonies. A careful comparison was made between the 4-month thermophilic granules and those obtained before the temperature shift or just 1 week after it, to detect changes in general structure and details that might have been set in motion by the rise in temperature. 

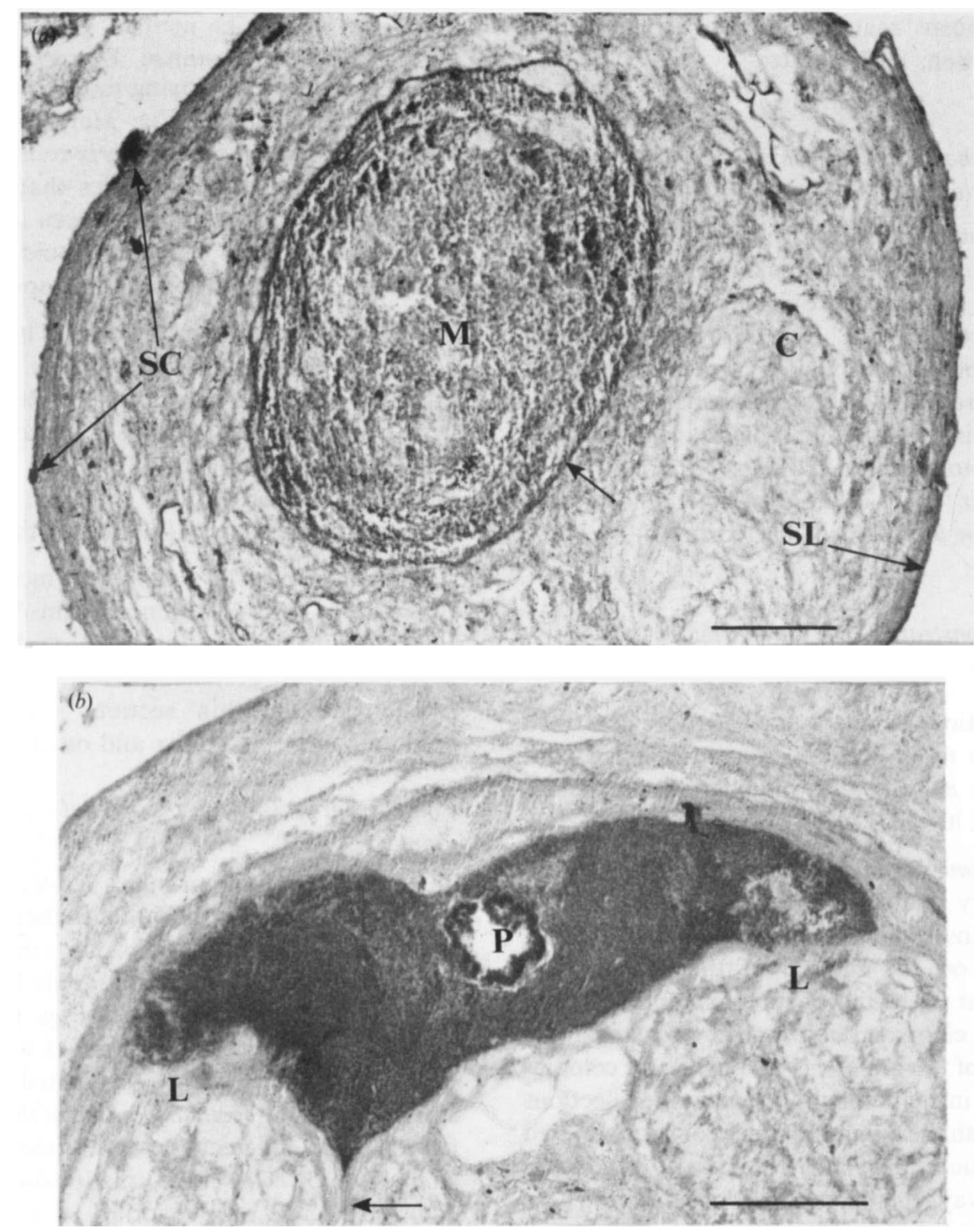

Fig. 1. (a) Panoramic view of a cross-section of a 4-month thermophilic granule showing the cortex (C) and medulla (M), the thin denser layer separating them (intercorticomedullary layer, arrow), the surface layer (SL) enveloping the granule, and two surface colonies (SC). (b) Large colony with the shape of a croissant in between layers at the corticomedullary interface. Within this colony, methanosarcinas form packets $(\mathrm{P})$ or a net of cellular cords (L). Note the subdivision of the medulla into two lobes by a septum (arrow) emerging from the intercorticomedullary layer, and the lax texture of both medulla and cortex with numerous empty irregular bubbles or elongated crevices. Haematoxylin/eosin. Bars: $20 \mu \mathrm{m}(a) ; 5 \mu \mathrm{m}(b)$.

\section{Results}

\section{Overall structure of 4-month thermophilic granules}

Fig. 1(a) shows the major features of the structure of the granule: a core or medulla surrounded by a wide peripheral zone or cortex. Thin, dense layers encircle the granule and the medulla. All these features were observed not only in granules maintained under thermophilic conditions, but also in those grown under mesophilic conditions, as shown below. Fig. $1(a)$ also shows two morphological details, i.e. a spongy texture and microbial colonies sitting on the surface, typical of the granules grown at $55^{\circ} \mathrm{C}$ for 4 months.

The general structural features demonstrated in Fig. 1(a) were observed in all thin sections examined, although some variations of detail did occur. For example, occasionally the medulla was subdivided into two or three lobes by dense layers branching off the layer separating the medulla from the cortex (Fig. $1 b$ ) and 
areas of homogeneous material were observed in the medulla or, less often, in the cortex.

\section{Microbial groups shown by general stains in 4-month thermophilic granules}

Sitting on the outer layer of all granules were dense colonies flat and elongated with thicker zones resembling mounds that were more clearly evident in haematoxylin/ eosin stained sections (Fig. 1 $a$ ). Also present in all granules was another conspicuous type of microbial colony that appeared with an elongated shape of various thicknesses, growing in the plane of cleavage between layers concentric to the medulla (Fig. 1b). Close to, or within this latter type of colony, methanosarcinas formed packets, or a net of cellular cords.

\section{Methanogens demonstrated with antibody probes in 4-month thermophilic granules}

All the observations below, as well as those described in the other sections of Results, were confirmed with granules from three different bioreactors run under thermophilic conditions.

Methanobacterium thermoautotrophicum. This methanogen, antigenically related to the reference strain $\Delta \mathrm{H}$, formed, in all granules examined, two types of colony: one type sitting on the surface of the granule and appearing as a flat layer and/or mounds, and a second type appearing as elongated half-moons, in between the concentric layers of the granule (Fig. $2 a$ ). These colonies were also visible in hematoxylin/eosin-stained sections (see Fig $1 a, b$ ). Both the outer and inner colonies adhered to the adjacent structural layer of the granule. If the outer layer was torn away, the colony went with it (Fig. 2b) (note the integrity of the outermost layer even after separation from the granule, indicative of a well-defined and firm, flat structure like a capsule; also note the adherence of the bacterial colony to the capsule). If the granule was overstretched, inner colonies split in two with the halves sticking to each adjacent layer (Fig. 2c). This suggests a strong adherence of the bacterial colony to the surrounding layers.

Methanosarcina. The Methanosarcina species, antigenically closely related to $M$. thermophila TM1, appeared in all granules as globular aggregates of packets, usually in the outer portion of the cortex (Fig. $3 a$ ), or as a net of cellular cords in the medulla and, more frequently, in the cortex (Fig. $3 b$ ). Packets and cords were found closely associated with colonies of the methanogen related to Methanobacterium thermoautotrophicum $\Delta \mathrm{H}$ (see Fig. $1 b$ ).
Methanothrix. The methanogen antigenically related to the reference organism $M$. soehngenii Opfikon was found in bundles occupying mostly the interstices of the cortex of all granules. Fig. 3(c) shows short and very short pieces of the Methanothrix rods resulting from the cross-sectioning of the bundles that have been recognized by the probe and can be seen in between cords of unreactive material. The latter could be an intercellular substance and/or other microbial species.

Methanobrevibacter arboriphilus. The methanogen antigenically related to $M$. arboriphilus $\mathrm{AZ}$ formed, in all granules, a lawn of evenly distributed cells of variable densities throughout portions of the cortex and extending into the medulla (Fig. 3d). The presence of this methanogen was limited to small areas of the thin sections, and to only a fraction of the latter.

Methanobrevibacter smithii. The methanogen antigenically related to the reference strain ALI formed a lawn similar to that shown in Fig. 3(d), but sparser. It was observed in all granules in restricted areas of only a fraction of the thin sections examined, occupying predominantly the cortex and outer medulla.

\section{Comparison of 4-month thermophilic granules with other granules}

Neither mesophilic granules grown in the same or different substrate as the 4-month thermophilic granules, nor granules grown in the same substrate at the same temperature (i.e. $55^{\circ} \mathrm{C}$ ), but for only 1 week, showed the colonies described above (see Figs 1-3). The granules that had been maintained for only 1 week in acetate/propionate/butyrate at $55^{\circ} \mathrm{C}$ presented, in rare sections, small colonies of Methanobacterium thermoautotrophicum (which were undetectable before the temperature raise from 38 to $55^{\circ} \mathrm{C}$ ). These small colonies were thin and flat, and located on the surface of the granule, or were little groups of cells located in the cortex (not shown). Both types of incipient colonies represented the initial stages of the much larger, denser and more numerous colonies observed 4 months later (see Fig. 2).

The colonies of the methanosarcina antigenically closely related to Methanosarcina thermophila TM1, which were so conspicuous in the granules maintained at $55^{\circ} \mathrm{C}$ for 4 months (Figs $1 b, 3 a, b$ ), were very rare in the mesophilic granules and in those maintained at $55^{\circ} \mathrm{C}$ for only a week. Instead, in these granules, small colonies of cells closely related to the reference organism Methanosarcina barkeri $\mathrm{W}$ were observed. The majority of these colonies were formed by the single-celled phenotype characteristic of strain W (not shown).

The mesophilic granules, and the granules maintained under thermophilic conditions for only 1 week, showed a more compact fabric than that of the 4-month thermo- 

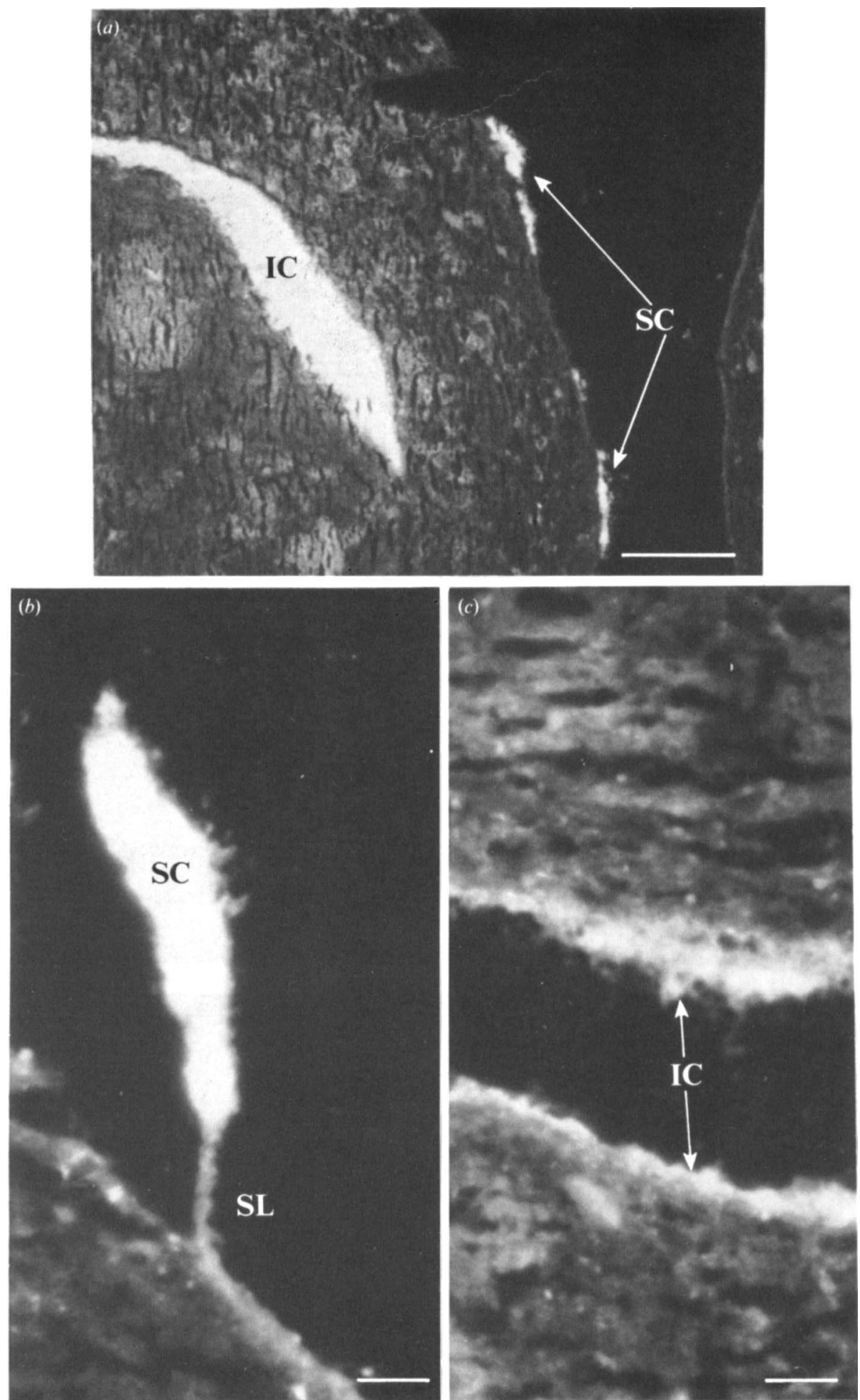

Fig. 2. (a) Panoramic view of a cross-section of a 4-month thermophilic granule showing an inner colony (IC) and surface colonies (SC) characteristic of the methanogen antigenically related to Methanobacterium thermoautotrophicum. (b) The surface layer (SL) of the granule has been torn away from the cortex carrying with it a surface colony (SC). (c) Split inner colony (IC); the colony halves adhere onto the corresponding supporting layers that have been separated from each other by overstretching. Indirect immunofluorescence with an antibody probe for strain $\Lambda \mathrm{H}$. Bars: $20 \mu \mathrm{m}(a) ; 2 \cdot 5 \mu \mathrm{m}(b, c)$. 

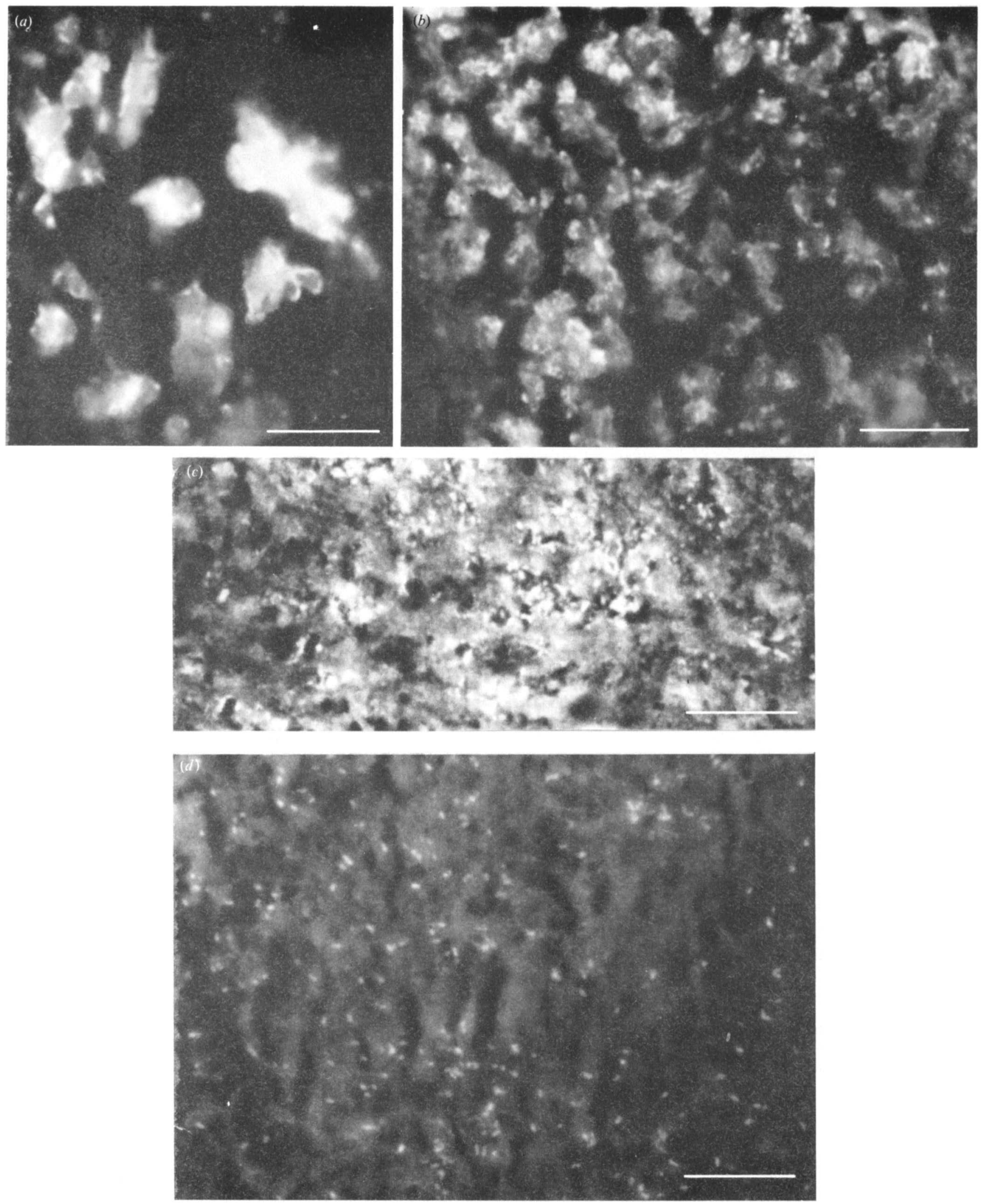

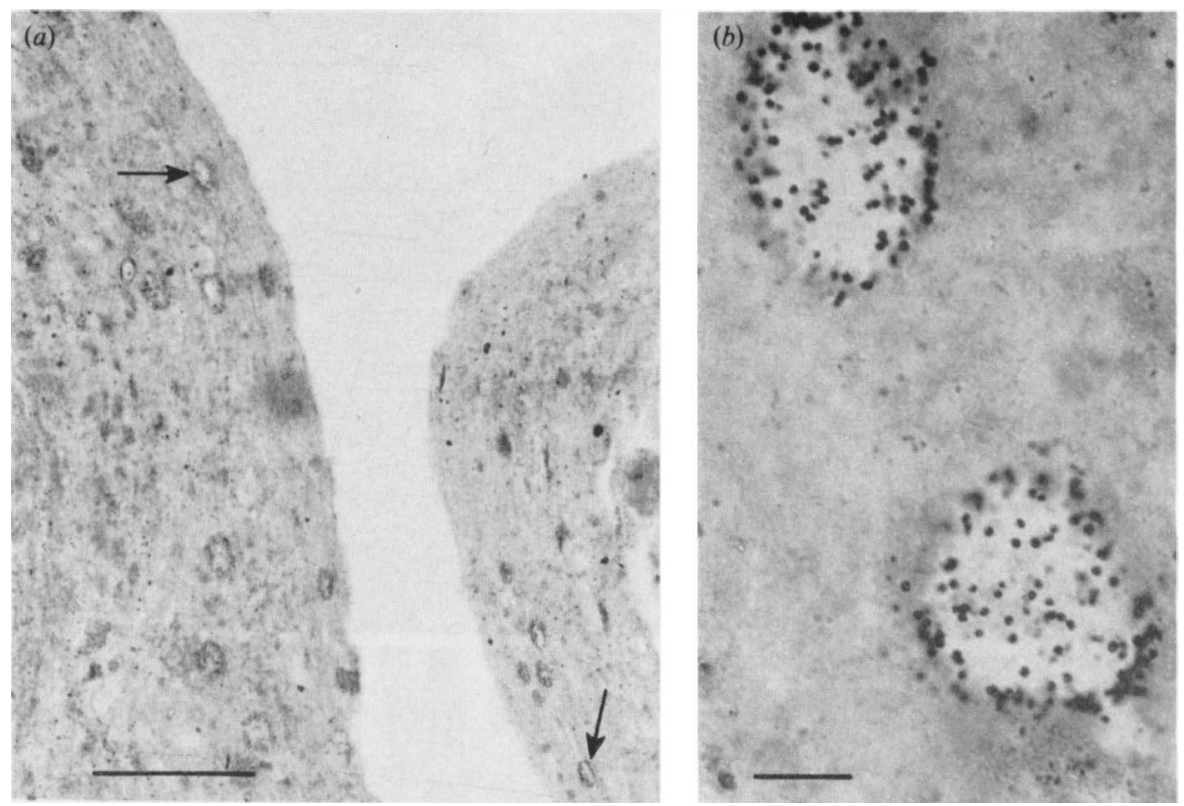

Fig. 4. (a) Two adjacent thin sections of a mesophilic granule displaying circular arrays of cells inside the cross-section of 'tubes' (two of which are shown by arrows) located for the most part in the outer half of the cortex. Hematoxylin/eosin; bar, $20 \mu \mathrm{m}$. (b) High magnification of the 'tubes' with cells inside in the cortex of a mesophilic granule. Gram; bar, $2.5 \mu \mathrm{m}$.

philic granules. The latter granules (see Fig. $1 a, b$ ) showed many elongated cavities. Instead, the thin sections of mesophilic granules showed circular cavities most likely representing the cross-section of tubes running through the outer half of the cortex (Fig. 4a), and having round cells inside (Fig. $4 b$ ). These 'tubes' disappeared rapidly following the temperature shift from 38 to $55^{\circ} \mathrm{C}$, and were barely discernible 1 week thereafter (results not shown).

All these differences in texture and details of organization between the granules maintained for 4 months under thermophilic conditions and other granules were confirmed in all specimens examined, and were manifest regardless of the staining method used - haematoxylin/ eosin, Gram, PAS and silver impregnation. The latter method showed a profusion of filaments mostly in the cortex of both mesophilic and 4-month thermophilic granules, but in an irregular, curly arrangement in the former (Fig. 5a), as opposed to a somewhat more organized disposition in layers in the 4-month thermophilic granules, (Fig. $5 b$ ). In the latter figure, it can be seen that the filaments formed a lax arrangement running concentric to the medulla and delimiting elongated empty spaces typical of the spongy structure of the 4-month thermophilic granules. Cocci are scattered amidst the filaments. No circular array of cocci inside 'tubes', like those typical of mesophilic granules, is discernible. In Fig. 5(a), the 'tubes' with round cells inside typical of mesophilic granules (see Fig. $4 b$ ) can be distinguished amidst the filaments. Likewise, the surface colonies (formed by the methanogen related to Methanobacterium thermoautotrophicum $\Delta \mathbf{H}$; see Fig. $2 b$ ) characteristic of the 4-month thermophilic granules were discernible in a space dissected between the filaments and the outermost layer (Fig. $5 c$ ). Note the clear-cut limits of the colony and its extensive contact with the filaments, which do not penetrate the colony.

Both types of granules showed a denser band bounding the cortex on the outside formed by filaments closely intertwined (Fig. 5a,b). This band corresponds to the outer layer or capsule demonstrated by other methods (see, e.g., Figs $1 a$ and $2 b$ ).

Fig. 3. Fourth-month thermophilic granules. $(a, b)$ Methanosarcina colonies in the outer zone of the cortex demonstrated by indirect immunofluorescence using an antibody probe for Methanosarcina thermophila TM1. The colony in $(a)$ is formed by packets and aggregates thereof, whereas the colony in $(b)$ is constituted of cellular cords, like those in Fig. $1(b)$, P and L, respectively. Bars, $5 \mu \mathrm{m}$. (c) Detail of the cortex shown by indirect immunofluorescence with an antibody probe for Methanothrix soehngenii Opfikon. Bar, $5 \mu \mathrm{m}$. $(d)$ Sparse lawn of the methanogen antigenically related to Methanobrevibacter arboriphilus on adjacent areas of the cortex and medulla demonstrated by indirect immunofluorescence with an antibody probe for strain AZ. Bar, $5 \mu \mathrm{m}$. 

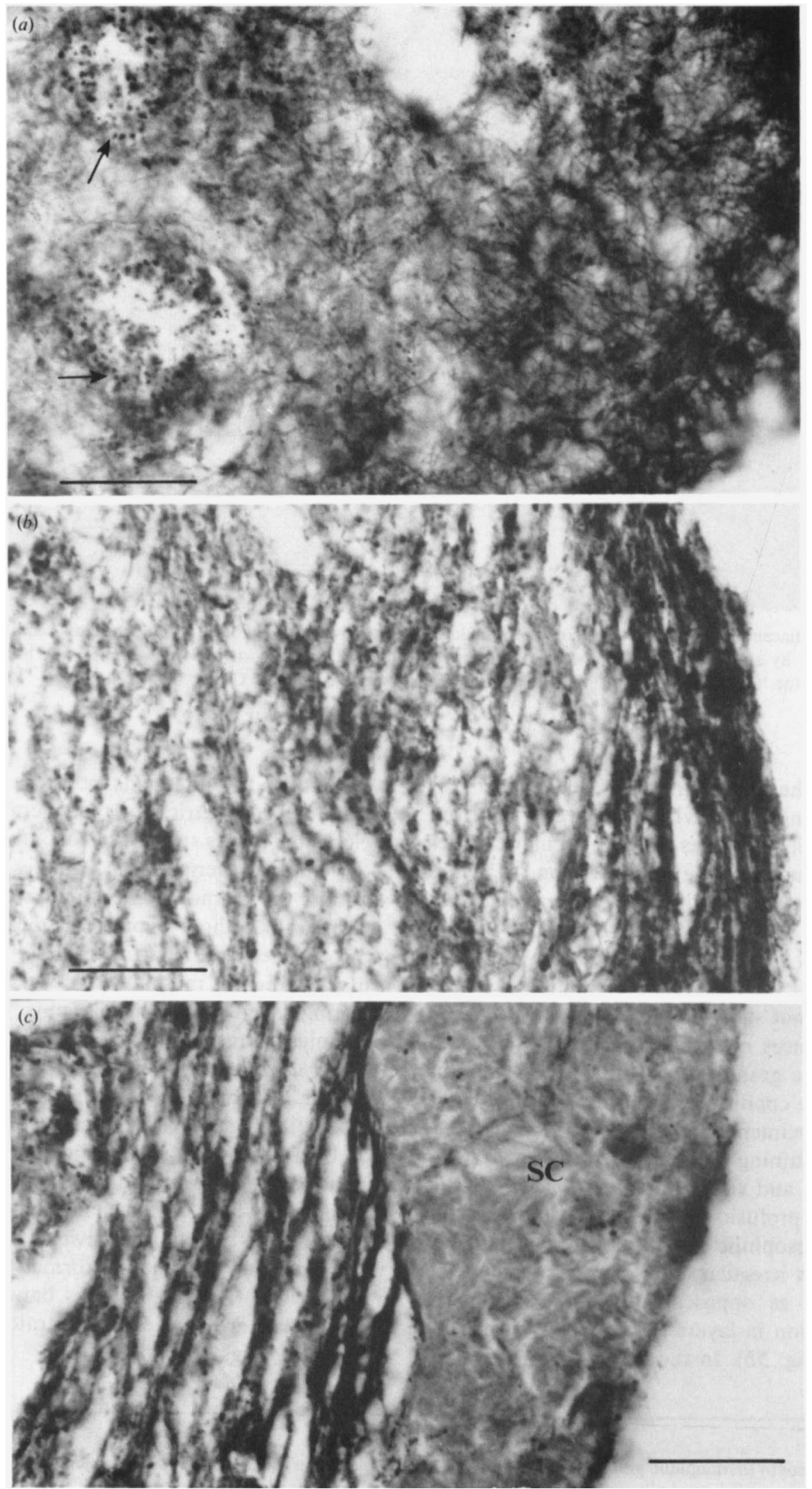

Fig. 5. (a) Detail of the cortex of a mesophilic granule, near the surface, showing many filaments of fibres in a curly, irregulat distribution with a few scattered small cocci and two large circular arrays of cocci (arrows) corresponding to the 'tubes' with cells inside shown in Fig. 4. (b) Detail of the cortex of a thermophilic granule, near the surface, to be compared with a similar zone of a mesophilic granule shown in $(a)$. (c) Surface colony (SC) like those shown in Fig. $2(a, b)$ but larger, in between the filaments and the outermost layer of the granule. Silver impregnation; bars, $5 \mu \mathrm{m}$. 

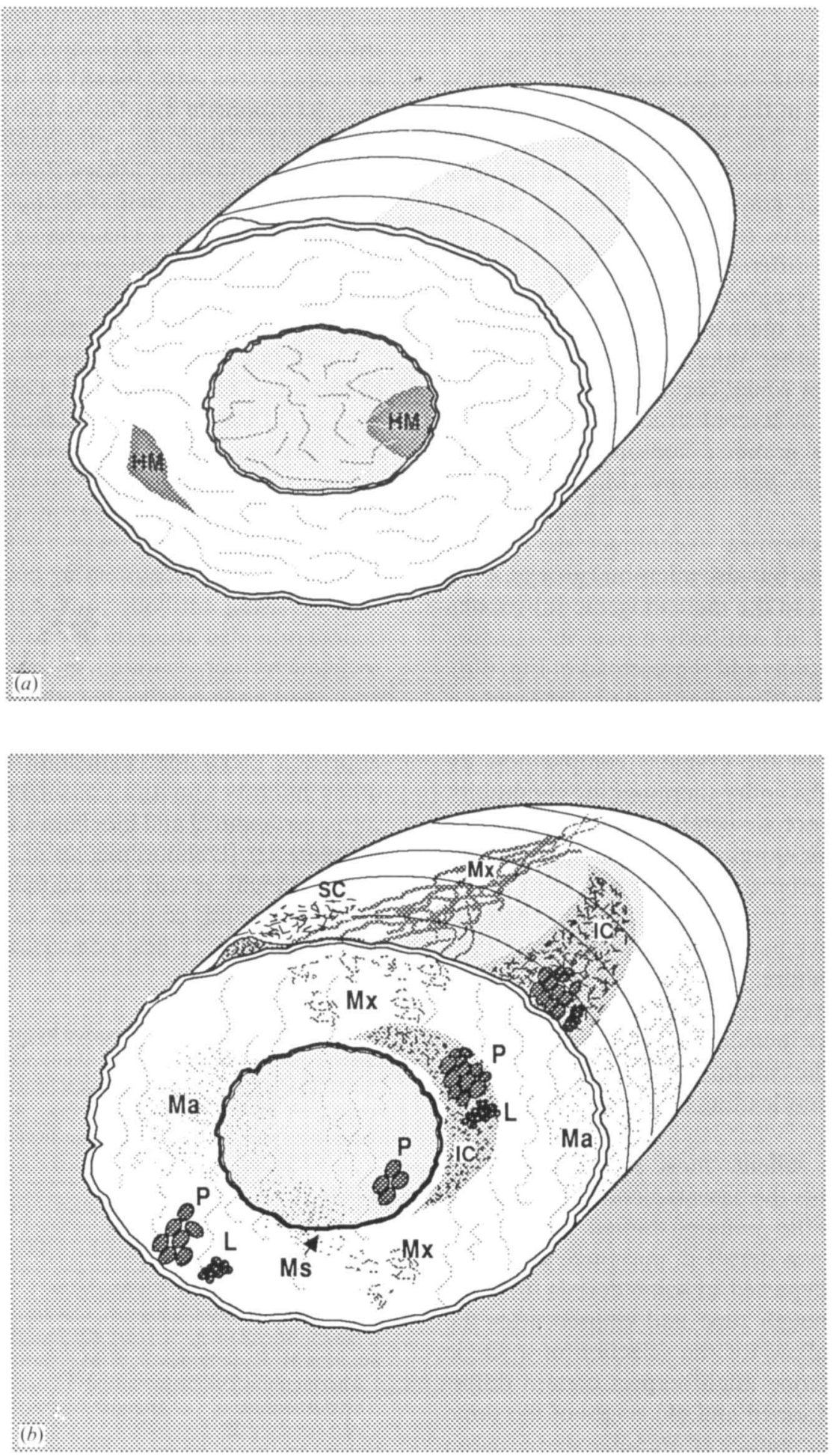

Fig. 6. Schematic representation of a 4-month thermophilic granule. (a) Matrix onto which methanogens are lodged. Although the matrix has been drawn as a loose net only in the frontal section, it is probably denser and spans the whole granule being formed by microbes and intercellular substance. HM, homogeneous material. (b) Reconstructed tridimensional aggregates or bundles for the following methanogenic subpopulations: Methanobacterium thermoautotrophicum, surface and inner colonies (SC and IC, respectively); Methanosarcina thermophila, packets (P) and cellular cords (L); Methanothrix rods (Mx), bundles of more or less intertwined filaments; Methanobreribacter arboriphilus $(\mathrm{Ma})$, clouds that appear as more or less dense lawns in cross-section; and Methanobrevibacter smithii (Ms), thin clouds that show up as sparse lawns in cross-section. Although Methanothrix rods are drawn in only two areas, they are more generalized. 


\section{Discussion}

A shift from mesophilic to thermophilic conditions brought about changes in the methanogenic subpopulations and the granular structure: 4 months after the temperature shift, the granules showed typical features. These are summarized graphically in Fig. 6 with a tridimensional perspective reconstructed from examining thin-sections cut at different angles. The architecture of the granules is represented to include a supporting matrix (Fig. 6a) for the methanogenic subpopulations, probably formed by other microbes and intercellular material, and two major zones, cortex and medulla, with layers bounding them. A layered structure has also been described for another granular consortium examined using scanning electron microscopy (MacLeod et al., 1990).

The standard histochemical techniques showed not only these basic features, but also microbial groups, some of which corresponded to the methanogenic subpopulations demonstrated by the antibody probes in immunohistochemical preparations and represented in Fig. 6(b).

The data suggest that although the original mesophilic granules served as a carrier and support for the growth of thermophilic organisms, the granular compactness diminished after 4 months under thermophilic conditions. Since changes were not detectable after passing the granules from the donor bioreactor into the experimental bioreactors, but only after the temperature shift of the latter, the role of substrate change in causing structural modifications must have been much less important than the increase in temperature. This would tend to indicate that thermophilic start-up of UASB bioreactors using mesophilic granules as inoculum will not result, under continuing thermophilic conditions, in an enhancement of the granulation process leading to a compact microbial arrangement.

Fig. 6 reflects the salient, most common features observed, and represents the basic structure shared by all the 4-month thermophilic granules studied. However, a certain heterogeneity was detected, inasmuch as a small minority of granules departed in some details from the norm. Perhaps not enough time had elapsed after the temperature shift to allow for the selection of a single type of granule. Also, one might expect certain differences between newly formed and old stages of the same type of granule. Earlier studies of granular sludge using electron microscopy have shown details of discrete colonies, bundles of Methanothrix rods and close associations between different species embedded in a matrix with homogeneous material and fibrous structures (Dubourguier et al., 1988). Some of the methanogens and syntrophs were identified by immunoelectron microscopy with specific antisera in confined sectors of the colonies (Prensier et al., 1988). Our findings provide new insights into the actual size and location of methanogenic subpopulations with regard to the granule as a whole. The data indicate that the UASB granules have evolved a complex structure, presumably to achieve more efficient syntrophic associations, and that they can respond to environmental changes. Undoubtedly, these granules represent a challenging target for elucidating molecular and genetic mechanisms involved in the formation of multicellular structures by primitive life forms (i.e. methanogenic archaeobacteria).

Other noteworthy features of our work were: (i) the observation of two distinct colony types of sarcina, matching those identified in axenic cultures undergoing phenotypic conversion (Mayerhofer et al., 1990); and (ii) the agreement between the quantities of each methanogenic species determined in cell suspensions from disrupted granules (Visser et al., 1991), and the frequency and size of the corresponding colonies observed in thin sections using antibody probes (this report). While cell counts provided accurate quantitative data, immunohistochemistry corroborated in a general way those data and, most importantly, showed the location and distribution of each methanogenic subpopulation. Such a dual approach, if extended to include the use of probes for the other microbes in the consortium and to encompass immunochemical and biochemical analyses of intercellular material (Dubourguier et al., 1988; Prensier et al., 1988), should reveal the complete tridimensional arrangement and composition of the consortium and should provide clues concerning its formation and physiology.

This work was partially supported by grant no. 706IERBEA-85 from GRI-NYSERDA-NY Gas. We thank James S. Swab for assistance, Ulrich Rudofsky and Carl J. Eriole for their help with histochemical techniques, and Professors G. Lettinga, A. J. B. Zehnder and A. J. M. Stams for their stimulatory interest in this work

\section{References}

Balch, W. E., Fox, G. E., Magrum, L. J., Woese, C. R. \& Wolfe, R. S. (1979). Methanogens: reevaluation of a unique biological group. Microbiology Reviews 43, 260-296.

Bochem, H. P., Schoberth, S. M., Sprey, B. \& Wengler, P. (1982) Thermophilic biomethanation of acetic acid: morphology and ultrastructure of a granular consortium. Canadian Journal of Microbiology 28, 500-510.

Boone, D. R. \& Whitman, W. B. (1988). Proposal of minimal standards for describing new taxa of methanogenic bacteria. International Journal of Systematic Bacteriology 38, 212-219.

Chartrain, M. \& Zeikus, J. G. (1986). Microbial ecophysiology of whey biomethanation: characterization of bacterial trophic populations and prevalent species in continuous culture. Applied and Environmental Microbiology 51, 188-196.

Costerton, J. W., Cheng, K.-J., Geesey, G. G., Ladd, T. I., Nickel, J. C., Dasgupta, M. \& Marrie, T. J. (1987). Bacterial biofilms in nature and disease. Annual Review of Microbiology 41, 435-464. 
Culling, C. F. A., Allison, R. T. \& Barr, W. T. (1985). Cellular Pathology Techniques, 4th edn, pp. 1-642. London: Butterworths.

DoLfING, J. (1987). Microbiological aspects of granular methanogenic sludge, pp. 1-78. PhD thesis, Agricultural University Wageningen, The Netheriands.

Dubourguier, H. C., Prensier, G. \& Albagnac, G. (1988). Structural and microbial activities of granular anaerobic sludge. In Proceedings of the Workshop on Granular Sludge: Microbiology and Technology, pp. 18-33. Edited by G. Lettinga, A. J. B. Zehnder, J. T. C. Grotenhuis \& L. W. Hulshoff Pol. Wageningen, The Netherlands: Pudoc Publishers.

FORD, T. \& Mitchell, R. (1990). The ecology of microbial corrosion. Advances in Microbial Ecology 11, 231-262.

Hamilton, W. A. (1987). Biofilms: microbial interactions and metabolic activities. In Ecology of Microbial Communities, pp. 361385. Edited by M. Fletcher, T. R. G. Gray \& J. G. Jones. Cambridge: Cambridge University Press.

Hulshoff Pol, L. W., de Zeeuw, W. J., Velzeboer, C. T. M. \& LETTINGA, G. (1983). Granulation in UASB reactors. Water Science Technology 15, 291-304.

Lettinga, G., van Velzen, A. F. M., Hobma, S. W., De Zeeuw, W. J. \& KLAPWIJK, A. (1980). Use of the upflow sludge blanket (USB) reactor concept for biological wastewater treatment, especially for anaerobic treatment. Biotechnology and Bioengineering 22, 699-734.

LuNA, L. G. (1968) (editor). Manual of Histologic Staining Methods of the Armed Forces Institute of Pathology, 3rd edn. New York: McGraw-Hill.

Macario, A. J. L. \& Conway de Macario, E. (1983). Antigenic fingerprinting of methanogenic bacteria with polyclonal antibody probes. Systematic and Applied Microbiology 4, 451-458.

Macario, A. J. L. \& Conway de Macario, E. (1985). Monoclonal antibodies of predefined molecular specificity for identification and classification of methanogens and for probing their ecological niches. In Monoclonal Antibodies against Bacteria, vol. 2, pp. 213-247. Edited by A. J. L. Macario \& E. Conway de Macario. Orlando, Fla.: Academic Press.

Macario, A. J. L. \& Conway de Macario, E. (1988). Quantitative immunologic analysis of the methanogenic flora of digestors reveals a considerable diversity. Applied and Environmental Microbiology 54, 79-86.
MacLeod, F. A., Guiot, S. R. \& Costerton, J. W. (1990). Layered structure of bacterial aggregates produced in an upflow anaerobic sludge bed and filter reactor. Applied and Environmental Microbiology 56, 1598-1607.

Margulis, L., Chase, D. \& Guerrero, R. (1986). Microbial communities: invisible to the scrutiny of naturalists, most microbial communities have escaped description. BioScience 36, 160-170.

MAYerhofer, L. E., Conway de Macario, E. \& Macario, A. J. L. (1990). Tissue-like forms of Methanosarcinae: structural and molecular analysis. Federation Proceedings 4, A770.

NovaEs, R. F. V. (1986). Microbiology of anaerobic digestion. Water Science Technology 18, 1-14.

Prensier, G., Dubourguier, H. C., Thomas, I., Albagnac, G. \& Buisson, M. N. (1988). Specific immunological probes for studying the bacterial association in granules and biofilms. In Proceedings of the Workshop on Granular Sludge: Microbiology and Technology, pp. 55-61. Edited by G. Lettinga, A. J. B. Zehnder, J. T. C. Grotenhuis \& L. W. Hulshoff Pol. Wageningen, The Netherlands: Pudoc Publishers.

Stams, A. J. M., Grotenhuis, J. T. C. \& Zehnder, A. J. B. (1989). Structure-function relationship in granular sludge. In Recent Advances in Microbial Ecology, pp. 440-445. Edited by T. Hattori, Y. Ishida, Y. Maruyama, R. Y. Morita \& A. Uchida. Tokyo: Japan Scientific Society Press.

Toerien, D. F. \& Hattingh, W. H. J. (1969). Anaerobic digestion. I. The microbiology of anaerobic digestion. Water Research 3, 385-416.

Visser, F. A., van Lier, J. B., Macario, A. J. L. \& Conway De MACARIO, E. (1991). Diversity and population dynamics of methanogenic bacteria in a granular consortium. Applied and Environmental Microbiology 57, 1728-1734.

DE ZeEUW, W. J. (1988). Granular sludge in UASB reactors. In Proceedings of the Workshop on Granular Sludge: Microbiology and Technology, pp. 132-145. Edited by G. Lettinga, A. J. B. Zehnder, J. T. C. Grotenhuis \& L. W. Hulshoff Pol. Wageningen, The Netherlands: Pudoc Publishers.

ZELlNER, G. \& WINTER, J. (1987). Analysis of a highly efficient methanogenic consortium producing biogas from whey. Systematic and Applied Microbiology 9, 284-292. 